Vol. 2, n. 3 - Edição Especial: Ciclos Formativos em Ensino de Ciências.

\title{
Meu primeiro pé de feijão
}

\author{
My first beanstalk
}

Mari Soni Marques Petry (marisoni32cre@gmail.com)

Universidade Federal da Fronteira Sul - UFFS

\begin{abstract}
Resumo: Atividades práticas nas aulas de Biologia são recursos auxiliares estratégicos no aprendizado de conceitos, além de tornarem o processo de ensino mais dinâmico por não restringir à memorização de conteúdos. E, se aplicada de modo generalizado e mais amplo, ou a outros campos que não os da Ciência, podem ser consideradas uma forma de raciocínio lógico, possível de ser empregado na resolução de vários problemas. Com atividades práticas os alunos desenvolverão habilidades fundamentais como a apropriação de ideias, a argumentação, a seleção de informações, o planejamento de ações, etc., as quais servirão de base na conquista da autonomia de pensamento e no desenvolvimento da sua capacidade crítica. Foi com esses objetivos que essa atividade foi desenvolvida durante três semanas e que será aqui compartilhada. Pois a sistematização de práticas através do relato de experiência é indicial para a formação de professores de Ciências, uma vez que o diálogo, a leitura e o espelhamento de práticas desencadeiam no grupo de formação, reflexão, socialização e estímulo para refletir o significado das escolhas feitas na ação profissional.
\end{abstract}

Palavras chave: Ensino de Botânica; Reflexão da experiência; Germinação.

Resume: Practical activities in biology classes are strategic auxiliary resources for learning concepts, and make the teaching process more dynamic by not restricting the memorization of content. And if applied broadly and broadly, or to fields other than those of science, they can be considered a form of logical reasoning that can be employed in solving various problems. With practical activities students will develop fundamental skills such as the appropriation of ideas, argumentation, selection of information, planning of actions, etc., which will serve as the basis for achieving autonomy of thought and developing critical capacity. It was with these goals that this activity was developed over three weeks and will be shared here. For the systematization of practices through the experience report is indicative for the formation of science teachers, since dialogue, reading and mirroring of practices trigger the formation, reflection, socialization and stimulation group to reflect the meaning of the choices. made in professional action.

Key words: Botany Teaching; Reflection of the experience; Germination. 
Vol. 2, n. 3 - Edição Especial: Ciclos Formativos em Ensino de Ciências.

\section{INTRODUÇÃO}

Meu primeiro pé de feijão é o relato de mais uma das experiências que realizei com meus alunos em uma aula de Biologia e que achei interessante e oportuno relatar aqui porque além de estar utilizando de um processo metodológico diferenciado para a aquisição do conhecimento científico, tornou minha aula mais interessante e significativa, além de incentivar o protagonismo do aluno através de um experimento simples que foi a germinação de sementes.

\section{METODOLOGIA}

A experiência que vou relatar, aconteceu no mês de agosto do ano de 2018 e é sobre a germinação da semente. A técnica, eu uso todo ano quando trabalho o Reino Plantae, mas dessa vez o procedimento foi diferente. Ao invés de fazermos um germinador coletivo na escola, cada aluno fez o seu germinador em casa e ficou responsável por ele e também com o compromisso de fazer um relatório dos eventos ocorridos por três semanas. Foi a primeira vez que procedi dessa forma.

Há um mês atrás, quando trabalhava o processo de reprodução das Angiospermas, com os terceiros anos do Ensino Médio, na Escola Estadual de Educação Básica Érico Veríssimo no município de Roque Gonzales, numa aula de Biologia, pedi que cada aluno escolhesse algumas sementes maduras e fizesse o seu germinador em casa.

Depois algumas dicas de como proceder, que materiais utilizar e esclarecer algumas dúvidas, eles começam a atividade. Para melhor observar, fizeram a germinação num copo transparente com algodão.

A maioria observou a germinação da semente de feijão, mas teve quem usou sementes de soja, de milho, de laranja e de abóbora. Essa variedade de sementes serviu para que os alunos pudessem perceber as diferenças entre o tempo de germinação entre as espécies e as variáveis que cada um estava controlando como a quantidade de água, a luminosidade e o calor do sol. 
Vol. 2, n. 3 - Edição Especial: Ciclos Formativos em Ensino de Ciências.

\section{RESULTADOS}

Atividades práticas como esta, devem ser bem estimuladas previamente para que possibilitem ricas experiências de aprendizagem e cumpram um importante papel pedagógico, para que desperte a curiosidade, estimule a busca pelo conhecimento, exercite certas habilidades e também exercite a prática de alguns valores e atitudes que nem sempre são exploráveis em sala de aula. Entre as habilidades específicas que podem ser exploradas estão: a observação, a busca, a coleta, a sistematização. No tocante aos valores, constitui uma oportunidade de compartilhar experiências, ideias, etc. e de respeitar o outro (a vida, o ambiente, as plantas e os colegas).

Uma atividade que desperta o interesse do aluno e que é capaz de estimular sua participação ativa, despertando sua curiosidade e favorecendo efetivo envolvimento na aprendizagem, leva também o educador refletir e repensar suas práticas.

Pensando nessa atividade como uma opção para a aula tradicional, o papel do professor como motivador, incentivador é muito importante. De acordo com a teoria sócio-histórica de Vigotski (2001, [s.p.]):

\footnotetext{
o professor deve ser o parceiro mais capaz em sua relação com os alunos, e não ser considerado como igual. Além de ser o responsável pela organização do processo e garantir as interações sociais que levarão ao aprendizado, o professor deve trazer conhecimentos novos.
}

Essa foi uma atividade diferente, que mexeu com a turma. Pois via eles trocando fotos e comentários sobre o estágio que suas sementes se encontravam, faziam comparações, buscavam os nomes das estruturas que iam surgindo na nova plantinha, reavaliaram suas atividades com muito empenho. Trocavam informações com os colegas, caso algum evento demorava para ocorrer ou acontecia muito diferente, iam verificar o que tinha ocorrido. Alguns tiveram que recomeçar a experiência: porque pôs muita água, pouca água, ou por ter esquecido no sol ou ainda porque pegou sementes imaturas. Um aluno relatou que dava "banho de sol" todo dia na sua plantinha e à noite trazia para dentro de casa. 


\section{Vol. 2, n. 3 - Edição Especial: Ciclos Formativos em Ensino de Ciências.}

A riqueza de um trabalho como esse, está na simplicidade do experimento. Para muitos da turma não se tratava do primeiro pé de feijão que vira germinar no copo, mas o primeiro que ele fizera, que ele tivera que manipular, que tivera de ser o responsável pela coleta de dados e pela análise dos mesmos e que tivera de tirar conclusões. É nesse sentido que essa atividade fez todo o sentido. Através dela desenvolvi alguns passos da experimentação, trabalhei conceitos da Botânica e ainda incentivei o protagonismo do aluno. Conforme Rosito (2000, p.197): “as atividades experimentais não devem ser desvinculadas das aulas teóricas, das discussões em grupo e de outras formas de aprender." Pois o que aprendemos com uma atividade prática, com uma pesquisa ou com informações recebidas seja pelas leituras de diversas formas recebidas ou compartilhadas, só se complementam e necessitam de um aprofundamento teórico.

Comparando com o modo que fazia antes o germinador na escola e deixava na sala de aula da turma para que eles observassem diariamente e relatassem os eventos, percebi agora mais envolvimento. Houve também mais autonomia do aluno, pois ele pode ser o coautor do seu próprio germinador com a responsabilidade e o compromisso em fazer o sistema funcionar. Mesmo que o relatório de alguns mais parecia um diário, outros fatores como o protagonismo, a paciência, a insistência e a persistência (considerados raros nos adolescentes) foram considerados. Uma vez que o aluno pode ou teve que manipular variáveis adaptativas ou de sobrevivência de sua plantinha.

Aqui entra um dado importante que todos nós, professores observamos no dia-a-dia na sala de aula: o interesse. No começo, a turma viu como mais uma tarefa extra e cansativa, que precisou de grande motivação. Mas já na primeira semana, o envolvimento foi aumentando e à medida que que os eventos foram surgindo, o interesse era bastante evidente. Durante as duas últimas semanas do experimento, quando as sementes começaram germinar, eu tinha dificuldade para seguir com o conteúdo previsto. A turma queria continuar mostrando fotos, trocando informações e seguir nas discussões sobre o germinador. Por mais que fosse individual a tarefa, sentiam necessidade de compartilhar seus resultados. E eu pedia: "Coloquem as discussões todas no relatório". 


\section{Vol. 2, n. 3 - Edição Especial: Ciclos Formativos em Ensino de Ciências.}

Tanto empenho pela tarefa gerou apego pela plantinha. Enxergando-a como ser vivo e tal como é, precisa ser cuidado. Um aluno até escreveu no seu relatório: “[...] dá até pena de ter de colocar meu pé de feijão fora, ele tá tão grande que começou murchar". Tanto que muitos dos alunos transplantaram-na para a terra para que pudessem continuar cuidando e observando melhor.

Como professora de Ciências e Biologia do Ensino Fundamental e Médio de uma escola da rede pública de ensino, há 28 anos, tenho convivido com as dificuldades comuns a todas as escolas públicas como: falta de materiais, falta de laboratórios apropriados, falta de tempo, de espaço, de pessoal para monitoramento e assessoramento. Essas angústias e a falta de tecnologias nas escolas tem desmotivado e até "privado" ou até podado um trabalho eficiente do professor que acaba ficando com um grande número de aulas semanais e não conciliando com todas as tarefas que sua profissão exige. Diante disso, poucas são as possibilidades que o professor acaba tendo para o seu preparo. Mas o que eu quero dizer é que não precisamos de experimentos vultuosos, técnicas aperfeiçoadíssimas para fazermos um trabalho interessante, motivador. Basta que seja instigante, tocante, que mexa com o aluno. Que venha de encontro aos interesses dos alunos e que sobretudo, promovam seu conhecimento e melhorem sua aprendizagem. De acordo com Ghedin, Oliveira e Almeida (2015, p. 227): “[...] ao realizar pesquisa [...] o professor torna-se capaz de ressignificar suas práticas pedagógicas de forma crítica [...] ele contribui com a formação de um sujeito autônomo e crítico".

Não sei se eles vão saber futuramente como se chama a primeira raiz da plantinha, mas via eles pesquisando seu nome no livro ou na internet, tirando fotos, compartilhando, motivadíssimos. Mas tenho certeza que não vão esquecer que a semente tem um embrião, que se nutre do endosperma e dos cotilédones, da importância da água para a germinação, etc. E que eles são capazes.

Observe as fotos que a aluna Kauani da turma 312, turno da tarde me enviou pelo whats app, encantada com os seus feijões: 
Vol. 2, n. 3 - Edição Especial: Ciclos Formativos em Ensino de Ciências.

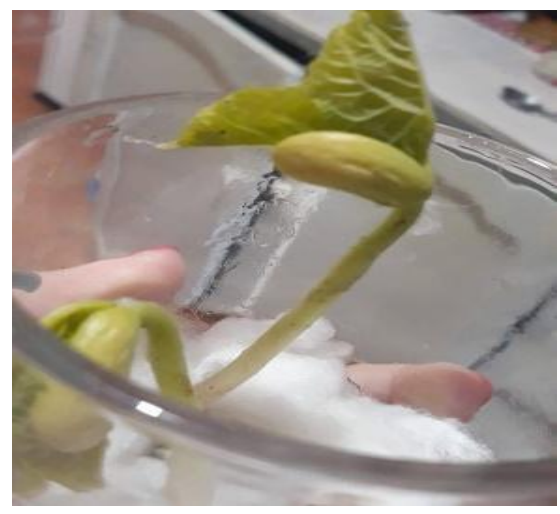

Figura 1: Foto de sementes de feijão germinando no copo, enviadas por uma aluna Fonte: Autora

Abaixo podemos observar fotos da plantação de feijão da aluna Kauani e, ao lado, de pés de milho transplantados, na horta, pela aluna Flávia, depois de fazer a germinação no copo.

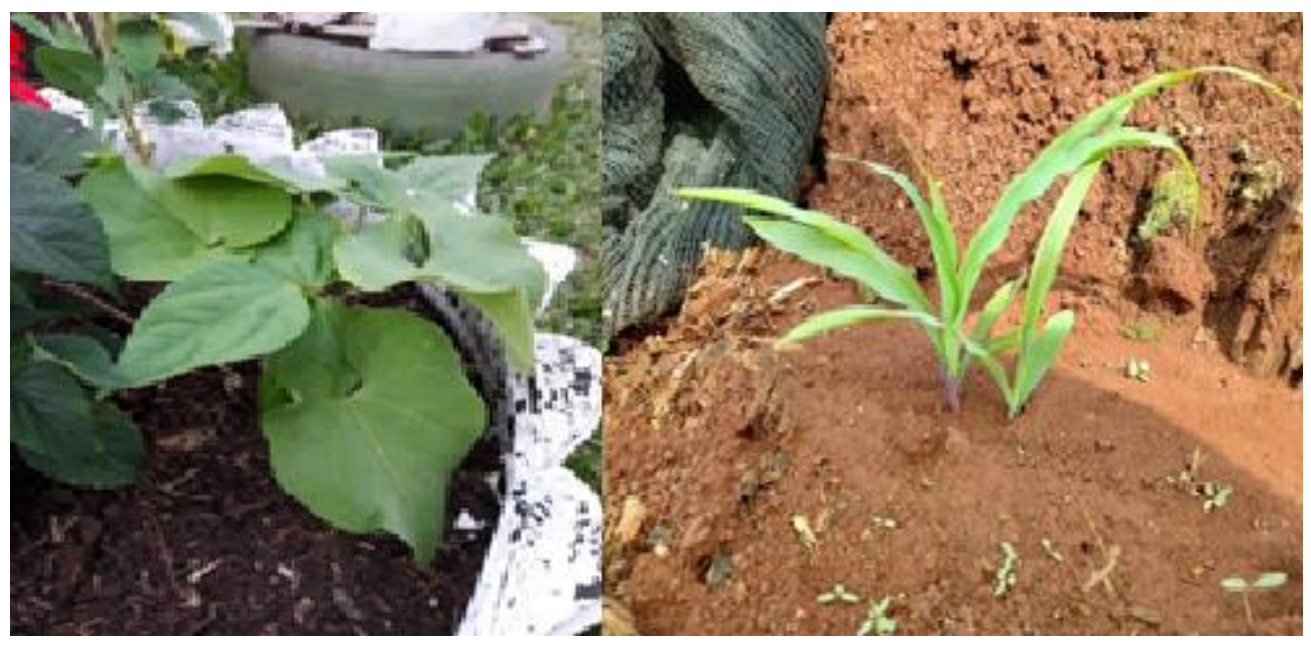

Figura 2: Fotos de feijão e milho transplantados, enviadas por uma aluna Fonte: Autora

\section{CONCLUSÃO}

Concluindo o relato Meu primeiro pé de feijão, me remeteu a escrever para compartilhar a ideia de que o conhecimento em sala de aula, não deve ficar centrado no professor. Deve também ver o aluno como protagonista de seu processo de aprendizagem e permitir oportunidades para que ele seja capaz de desenvolver capacidades de autonomia. 
Vol. 2, n. 3 - Edição Especial: Ciclos Formativos em Ensino de Ciências.

Ao professor cabe mediar esse processo e acompanhar desde o início da atividade até a sua finalização. É ele que abre os caminhos para que o estudante tenha interesse pelos conteúdos, pesquise e descubra a melhor maneira de absorvê-los. Outra vantagem considerável de transmitir o protagonismo é estimular sua capacidade criativa, sendo assim, o aluno passa a desenvolver melhor a capacidade de analisar situações, fazer escolhas, estabelecer metas, gerenciar melhor seus pensamentos e ainda melhorar a cooperação em sala de aula.

Em nossa área, há muitas formas de trabalhar teoria e prática. Temos a experimentação, as atividades de campo, as pesquisas. Todos podem nos fornecer dados para muitos esclarecimentos e crescimento pessoal.

\section{REFERÊNCIAS}

AMABIS, J. M e MARTHO, G. R. Germinação da Semente. In: AMABIS, J. M e MARTHO, G. R. (Orgs.) Biologia em contexto. Moderna: São Paulo,v.3, 2013.p. 79.

OSÓRIO, T. C. Estrutura e germinação das sementes. OSÓRIO, T. C. (Org.) Ser protagonista: Biologia Ensino Médio. Ed. SM: São Paulo, 2a Ed. v.2, 2013. p. 82

PERSON, Vanessa A., GÜLLICH, R. I. C. Demarcando elementos constitutivos da formação continuada de professores de Ciências. In: BONOTTO, Danusa de Lara; LEITE, Fabiane de Andrade. GÜLLICH, Roque I C. Movimentos Formativos: Desafios para pensar a educação em ciências e matemática. Tubarão: Copiart, 2016, p. 291-310.

ROSITO, B. A. O ensino de Ciências e a experimentação. In Moraes, R. (Org.). Construtivismo e ensino de ciências: reflexões epistemológicas. 3. ed. Porto Alegre: EDIPUCRS, 2008. p. 195-208.

SANTOS, E. I. Ciências nos Anos Finais do Ensino Fundamental: produção de atividades em uma perspectiva sócio-histórica. E.Anzol, São Paulo, 2012.

VIGOTSKI, L.S. A construção do pensamento e da linguagem. São Paulo: Martins Fontes, 2001. 